\title{
A dynamic biophysical fugacity model of the movement of a persistent organic pollutant (POP) in Antarctic marine food webs.
}

\author{
Roger Cropp ${ }^{\mathrm{A}, \mathrm{B}}$, Georgina Kerr ${ }^{\mathrm{A}}$, Susan Bengtson-Nash ${ }^{\mathrm{A}}$ and \\ Darryl Hawker ${ }^{A}$
}

${ }^{A}$ Atmospheric Environment Research Centre, School of Environment, Griffith University, Nathan, QId. 4111, Australia

${ }^{B}$ Corresponding author. Email: R.Cropp@griffith.edu.au

\section{Environmental Context}

Persistent organic pollutants (POPs) are potentially toxic chemicals, capable of long distance transport and are often found far from their source. Little is known of their behaviour in Antarctica, where the marine plankton food web is driven by strong seasonal variations in solar radiation. We present the first dynamic coupled ecosystem-fugacity model to describe how POPs distribute through the Antarctic environment. We use the model to identify the important processes that govern the presence of hexachlorobenzene (HCB) in Antarctic plankton.

\section{Keywords}

Persistent organic pollutants (POPs); plankton; dynamic coupled fugacity food web model; biomagnification factor; hexachlorobenzene (HCB); Antarctica. 


\section{Abstract}

Polar regions can be repositories for many persistent organic pollutants (POPs). However, comparatively little is known of the movement and behaviour of POPs in Antarctic ecosystems. These systems are characterised by strong seasonal effects of light on plankton dynamics. This work describes a mass-conserving, fugacity-based, dynamic model to describe the movement of POPs in the Antarctic physical and plankton systems. The model was developed by coupling a fugacity model of the physical Southern Ocean environment and a NutrientPhytoplankton-Zooplankton-Detritus (NPZD) ecosystem model with a biological fugacity model. The model is applied to the movement of hexachlorobenzene (HCB), a POP found in the Antarctic environment. The model predicts that the burden of HCB in the plankton varies with the seasonal cycle in Antarctic waters, and induces a seasonal variation in the biomagnification factor (BMF) of zooplankton. This suggests that time series of POP concentrations in Antarctic biotic and abiotic systems should be measured over complete seasonal cycles. Further, detritus is shown to be a key contributor to the movement of POPs in polar environments, linking physical and biological components of the model. 


\section{Introduction}

Persistent Organic Pollutants (POPs) are toxic man-made chemicals that do not readily degrade in the natural environment, have the capacity to bioaccumulate in food webs and may be subject to long range environmental transport, potentially reaching remote regions far from the emission sources.[1] They are regulated by the United Nations Environment Program's Stockholm Convention on POPs.[2] The original group of chemicals listed under the Stockholm Convention shared similar chlorinated aromatic structures that resulted in similar predicted environmental behaviour. Chlorinated POPs are hydrophobic and lipophilic with octanol/water partition coefficients $\left(K_{O W}\right)$ typically of the order of $10^{4}$ to $10^{7}$.[3] This combination of properties means that POPs have a propensity to bioconcentrate and bioaccumulate in living organisms, representing a significant risk to human and environmental health.

Since they are generally semi-volatile, volatilized fractions of legacy POPs and molecules adsorbed to fine particles may be transported great distances by air masses where they will undergo global fractionation processes along temperature gradients, favouring deposition in colder climates such as high altitude or latitude environments. The polar regions of the earth have been proposed as significant environmental repositories for many chemicals that can be transported by natural processes from their areas of use, and this view has been supported by direct observations of chemical distribution trends, primarily from the Arctic region. ${ }^{[4]}$ By contrast, the Antarctic region has not received the same degree of scrutiny. [5]

Polar marine environments are characterised by strong, seasonal variations in light, temperature and mixing[6] that drive the population dynamics of polar biological systems. Significant phytoplankton blooms occur in the spring and summer months and play a major role in biogeochemical cycling, including the cycling of POPs. Antarctic plankton ecosystems are generally simpler than their Arctic counterparts.[7] The dominant grazer species in Antarctic plankton ecosystems is the zooplankton species Euphausia superba (Antarctic krill), which 
forms the base diet of the majority of marine mammal predators.[8] Krill feed on phytoplankton, of which one of the most abundant species in Antarctic waters is the prymnesiophyte Phaeocystis spp. Phaeocystis is generally the first species to bloom in the Antarctic spring.[9]

Since POPs are by definition persistent, they have the ability to distribute between different environmental phases. Multimedia transport and fate models are useful tools with which to understand the behaviour of such compounds.[10] The basis of such models is the principle of mass balance in which the various processes affecting a chemical in a given phase are accounted for and can be expressed as a mass balance equation. By linking environmental phases, evaluative models describing broad behavioural patterns may be constructed. With sufficient data for the evaluative environment, realistic assessments of fate and behaviour can be made.[3] Such models often assume homogenous chemical distribution in a given phase, equilibrium partitioning and steady state. Hence they are well suited to POPs. Fugacity-based models, described in more detail below, have become prominent in this regard.[11] Regionalised versions of evaluative models focus on particular areas and use region-specific input data where possible and more complex spatially resolved fate models have also been developed.[12]

The movement of chemicals such as POPs in the environment can be described using the concept of fugacity.[13] Fugacity (literally "fleeing tendency", $f$ ) is an equilibrium criterion related to chemical potential that determines how a chemical will partition between multiple phases[11]. The rate of chemical movement between phases is proportional to the difference in fugacity. A chemical in diffusive equilibrium between two phases is unlikely to have the same concentration in the phases, but it will have the same fugacity. The fugacity $\left(f_{i}\right)$ of a phase $i$ is measured as a pressure $(\mathrm{Pa})$ and is related to concentration in the phase $\left(C_{i}, \mathrm{~mol} \mathrm{~m}^{-3}\right)$ by the expression:

$$
C_{i}=Z_{i} f_{i}
$$


where $Z_{i}$ is the fugacity capacity $\left(\mathrm{mol} \mathrm{m}^{-3} \mathrm{~Pa}^{-1}\right)$ of phase $i^{[11]}$ The fugacity approach has been used extensively to model the movement of POPs in physical systems, and in steady state POP distributions in food webs.[11,14-16]

The fugacity-based approach to model the movement of POPs in physical and biological systems has not to our knowledge been extensively applied to a dynamic Antarctic system. Consequently, the influence of the dynamics of the biological system on the movement of POPs within the physical system, particularly in environments such as Antarctic waters, is not well understood. The large plankton blooms typical of the Antarctic seasonal cycle produce large quantities of lipids, into which POPs partition in preference to other environmental phases or compartments such as air and water.[17] This suggests that a dynamic plankton food web model coupled to a fugacity model of the physical environment may provide useful insights into the seasonal dependency of the fate and behaviour of these compounds in Antarctic ecosystems.

The Nutrient-Phytoplankton-Zooplankton (NPZ) model is a generic tool used to describe the dynamics of many plankton ecosystems and is the optimal approach to modelling plankton ecosystems in the absence of detailed measurements of the population dynamics, ${ }^{[18]}$ as is the case in Antarctic marine plankton systems. NPZ models are mechanistic process-based models that include representations of phytoplankton uptake of nutrients, zooplankton consumption of phytoplankton and implicit microbial recycling of biological waste products back into the dissolved inorganic nutrient pool. They are often written in a currency of the limiting inorganic nutrient, which in the ocean is commonly nitrogen.[18]

The application of an NPZ model to modelling the movement of POPs through an ecosystem requires that a detritus compartment $(D$, composed of dead phytoplankton and zooplankton and their respiration products) be included, to give an NPZD model. Modelling detritus requires the explicit inclusion of an intermediate process as dead organic matter is recycled into the nitrogen pool via remineralization.[19] Detritus suspended in water is expected to play an important role in the partitioning of POPs as it provides the opportunity for POPs 
in dead organic matter to diffusively exchange with the water. The behaviour of POPs in an Antarctic plankton ecosystem can then be described by coupling the NPZD model to physical and biological fugacity models, allowing the simulation of POPs dynamically exchanging between the physical system and the plankton populations.

In this work we develop a fully coupled dynamic fugacity-based model that is driven by seasonal changes in the growth rate of phytoplankton that result from changes in the light field (a function of variations in solar radiance and the depth of the surface ocean mixed layer) and sea surface temperature. These seasonal forcings produce large vernal phytoplankton blooms in Antarctic waters. ${ }^{[20]}$ The model is then used to simulate the movement of hexachlorobenzene (HCB) in the Antarctic marine environment. Although the levels of HCB are reported to have fallen in the Antarctic environment in recent years, it is still a prevalent POP in remote regions. $[21,22]$

An axiomatic principle of models describing the movement of matter in an environment is that mass should be conserved.[3] The total mass of POPs in our closed physical-biological system remains constant over time and the distribution of POPs between phases is calculated. The contribution of model parameters to variations of POP fugacity in air, water, sediment, phytoplankton, zooplankton and detritus is examined using a sensitivity analysis.[23] Sensitivity analyses determine which parameters or processes have the most significant effect on the model output,[23] and should be undertaken before any multimedia chemical model is employed.[24] A sensitivity analysis is useful since it enables the determination of the most influential model parameters. This is essential for simulating ecosystems in which parameter values are poorly known as is generally the case for both ecosystem and fugacity models.[13, 25]

\section{Coupled Model}


The physical domain of the model was defined as a representative region of the Southern Ocean on the Antarctic continental shelf. It was assumed that the region is permanently free of sea ice. The physical domain of the model is a $1 \mathrm{~m}^{2}$ column of air, water and sediment that begins at the top of the atmospheric marine boundary layer, at a notional height of one kilometre, and extends through a mid-continental shelf water column of $100 \mathrm{~m}$ depth. It terminates in a layer of sediment on the ocean floor $0.05 \mathrm{~m}$ thick $\left(h_{S}\right)$ representing that part of the sediment that actively exchanges POPs with the overlying water. The physical domain assumes that the atmospheric and ocean layers are fully mixed and homogeneous, and that the whole of the sediment compartment exchanges POP with the water column above. The volume of air compartment $\left(V_{A}\right)$ is therefore $1000 \mathrm{~m}^{3}$, the volume of water compartment $\left(V_{w}\right)$ is $100 \mathrm{~m}^{3}$ and the volume of sediment compartment $\left(V_{S}\right)$ is $0.05 \mathrm{~m}^{3}$.

The coupled model (equations (2) - (24)) includes a fugacity based model of the physical environment that describes the partitioning of POPs amongst the air, water and sediment compartments, and a fugacity-based model that describes the partitioning of POPs among the compartments of an NPZD model (Figure 1). The NPZD model describes the changes in the populations of phytoplankton and zooplankton, and their waste products (detritus) in response to the availability of a limiting dissolved inorganic nutrient and changes in the environment as a result of seasonal cycles of solar irradiance, temperature, and the depth of the surface mixed layer. The NPZD model is written in a currency of atomic nitrogen as this is commonly the limiting nutrient in the ocean; however, we recognise that POPs typically move through the environment in association with carbon, and we therefore couple only the lipid content of the biota to the fugacity model assuming constant Redfield ratios.[26]

The physical fugacity model and the ecosystem model may be considered submodels that are coupled by the biological fugacity model. The physical and ecosystem sub-models are common models and will be described in the 
Supplementary Material. Only the insights into processes that arise from the dynamic coupling of the submodels will be considered here.

$$
\begin{aligned}
& V_{A} Z_{A} \frac{d f_{A}}{d t}=D_{A W}\left(f_{W}-f_{A}\right)-f_{A} \Phi A_{W}\left(U_{q} Q+U_{p}\right) Z_{x}-V_{A} f_{A} \frac{d Z_{A}}{d t}, \\
& V_{W} Z_{W} \frac{d f_{W}}{d t}=D_{A W}\left(f_{A}-f_{W}\right)+D_{S W}\left(f_{S}-f_{W}\right)+D_{P W}\left(f_{P}-f_{W}\right)+D_{Z W}\left(f_{Z}-f_{W}\right) \\
& +D_{D W}(1-\omega)\left(f_{D}-f_{W}\right)+f_{A} \Phi A_{W}\left(U_{q} Q+U_{p}\right) Z_{x} \\
& +f_{s} U_{r} A_{s} Z_{s}-f_{W} U_{d} A_{s} Z_{W}-V_{W} f_{W} \frac{d Z_{W}}{d t} \\
& V_{S} Z_{S} \frac{d f_{S}}{d t}=D_{S W}\left(f_{W}-f_{S}\right)+D_{D S} \omega\left(f_{D}-f_{S}\right)+f_{W} U_{d} A_{S} Z_{W}-f_{S} U_{r} A_{S} Z_{S}-V_{S} f_{S} \frac{d Z_{S}}{d t}, \\
& V_{P} Z_{P} \frac{d f_{P}}{d t}=D_{P W}\left(f_{W}-f_{P}\right)-f_{P} \rho_{P} Z_{P}\left(\mu \frac{N}{N+\kappa} P\right)-V_{P} f_{P} \frac{d Z_{P}}{d t}, \\
& V_{Z} Z_{Z} \frac{d f_{Z}}{d t}=D_{Z W}\left(f_{W}-f_{Z}\right)+\left(f_{P} \rho_{P} Z_{P}-f_{Z} \rho_{Z} Z_{Z}\right) \varphi P Z-V_{Z} f_{Z} \frac{d Z_{Z}}{d t} \\
& V_{D} Z_{D} \frac{d f_{D}}{d t}=D_{D S} \omega\left(f_{S}-f_{D}\right)+D_{D W}(1-\omega)\left(f_{W}-f_{D}\right) \\
& +\left(f_{P} \rho_{P} Z_{P}-f_{D} \rho_{D} Z_{D}\right) \sigma_{P} P+\left(f_{Z} \rho_{Z} Z_{Z}-f_{D} \rho_{D} Z_{D}\right)\left(\varphi \psi P Z+\sigma_{Z} Z\right), \\
& +f_{D} \rho_{D} Z_{D} v D-V_{D} f_{D} \frac{d Z_{D}}{d t} \\
& \frac{d N}{d t}=v D-\mu \frac{N}{N+\kappa} P, \\
& \frac{d P}{d t}=\mu \frac{N}{N+\kappa} P-\varphi P Z-\sigma_{P} P, \\
& \frac{d Z}{d t}=\varphi(1-\psi) P Z-\sigma_{z} Z, \\
& \frac{d D}{d t}=\sigma_{p} P+\sigma_{z} Z+\varphi \psi P Z-v D,
\end{aligned}
$$

where:

$$
\begin{gathered}
D_{A W}=k_{V} A_{W} Z_{W}, \\
D_{S W}=k_{T} A_{S} Z_{W}, \\
D_{P W}=k_{P D} \rho_{P} P Z_{P}, \\
D_{Z W}=k_{Z D} \rho_{Z} Z Z_{Z}, \\
D_{D W}=k_{D W} \rho_{D} D Z_{D},
\end{gathered}
$$




$$
\begin{gathered}
D_{D S}=k_{D S} A_{S} Z_{W}, \\
\rho_{P}=\xi_{P} \gamma_{P} V_{W}, \\
\rho_{Z}=\xi_{Z} \gamma_{Z} V_{W}, \\
\rho_{D}=\gamma_{D} V_{W} . \\
\mu=R_{L} R_{T} \hat{\mu}, \\
R_{L}=\frac{I_{A V}}{I_{A V}=I_{0} \int_{z=0} e^{+{ }^{+}\left(\frac{I_{A V} z}{I_{S A T}}\right)^{2}} d z=\frac{I_{0}}{k_{L} M L D}\left(1-e^{-k_{L} M L D}\right),} \\
R_{T}=e^{0.063\left(T-T_{M A X}\right)} .
\end{gathered}
$$

The parameter values for the model are given in Tables 1 and 2, and a full discussion of the model derivation is provided in the Supplementary Material. Note that the fugacity capacities $\left(Z_{i}=Z_{i}(T)\right)$ are dependent on temperature [11] details of which are given in Table 2 and the Supplementary Information.

The coupled model is implemented in a closed system, that is, a system that is open to fluxes of energy (solar radiation) but closed to fluxes of mass. The mass of all matter within the system must therefore be conserved, and this is an essential attribute of any model that is intended to describe the partitioning of a POP within an environment. For the purely physical system of air (a), water (W) and sediment $(\mathrm{S})$ in a constant temperature environment, conservation of mass implies the equation:

$$
V_{A} Z_{A} f_{A}+V_{W} Z_{W} f_{W}+V_{S} Z_{S} f_{S}=P O P_{T} \Leftrightarrow V_{A} Z_{A} \frac{d f_{A}}{d t}+V_{W} Z_{W} \frac{d f_{W}}{d t}+V_{S} Z_{S} \frac{d f_{S}}{d t}=0,
$$

where $V_{A}, V_{W}$ and $V_{S}$, and $Z_{A}, Z_{W}$ and $Z_{S}$ are the volumes and fugacity capacities of air, water and sediment respectively and $P O P_{T}$ is the total amount of POP in the environment. Equation (25) demonstrates that conservation of mass implies that the right-hand sides of the differential equations that describe the processes that control the movement of POP through the physical 
environment must sum to zero, and conversely if the right-hand sides of model equations sum to zero, the system conserves mass. This property provides an important analytic check on the model equations, and also provides a simple check on numerical solutions to the model that can be useful to identify programming errors.

The equation for conservation of mass of POPS for the coupled model in a dynamic environment is:

$$
V_{A} Z_{A} f_{A}+V_{W} Z_{W} f_{W}+V_{S} Z_{S} f_{S}+V_{P} Z_{P} f_{P}+V_{Z} Z_{Z} f_{Z}+V_{D} Z_{D} f_{D}=P O P_{T},
$$

where $V_{P}, V_{Z}$ and $V_{D}$, and $Z_{P}, Z_{Z}$ and $Z_{D}$ are the volumes and fugacity capacities of phytoplankton, zooplankton and detritus respectively. The fugacity capacities of all compartments are sensitive to temperature, so in a seasonally varying environment these will change seasonally (i.e. $Z_{i}=Z_{i}(T)$ where $T(t)$ is seasonally varying temperature) and this will influence the fugacity of all compartments. Similarly, as the volumes of phytoplankton, zooplankton and detritus vary as the populations grow and decline over a season, this will directly affect the fugacity of POP in the biological compartments, and indirectly affect the fugacity of POP in the physical compartments. Differentiating equation (26) with respect to time reveals that in contrast to the physical fugacity model in a constant temperature environment, for the coupled model to conserve mass in an environment with seasonal temperature variations, the right hand sides of the equations describing how fugacity changes over time do not sum to zero:

$$
\begin{aligned}
& V_{A} Z_{A} \frac{d f_{A}}{d t}+V_{W} Z_{W} \frac{d f_{W}}{d t}+V_{S} Z_{S} \frac{d f_{S}}{d t}+V_{P} Z_{P} \frac{d f_{P}}{d t}+V_{Z} Z_{Z} \frac{d f_{Z}}{d t}+V_{D} Z_{D} \frac{d f_{D}}{d t} \\
& =-\frac{d Z_{A}}{d t} V_{A} f_{A}-\frac{d Z_{W}}{d t} V_{W} f_{W}-\frac{d Z_{S}}{d t} V_{S} f_{S}-\frac{d Z_{P}}{d t} V_{P} f_{P}-\frac{d Z_{Z}}{d t} V_{Z} f_{Z}-\frac{d Z_{D}}{d t} V_{D} f_{D} . \\
& -\frac{d V_{P}}{d t} Z_{P} f_{P}-\frac{d V_{Z}}{d t} Z_{Z} f_{Z}-\frac{d V_{D}}{d t} Z_{D} f_{D}
\end{aligned}
$$

Equation (27) identifies that corrections must be made to the right-hand sides of the equations describing the fugacities of the biological compartments. The fugacity capacity correction terms, of the form $\frac{d Z_{i}}{d t} V_{i} f_{i}$ where $i$ indicates both the physical and biological compartments of the model, represent the change in fugacity of the chemical in the compartments that occurs as a result of 
temperature-induced changes in fugacity capacity. These correction terms adjust the fugacity of POP in a compartment that changes temperature, to ensure that the change in temperature does not cause the creation or extinction of POP mass. The change in fugacity due to a change in temperature induces a transfer of mass over time to return the compartment to an equilibrium state with its neighbours.

Similarly, correction terms of the form $\frac{d V_{j}}{d t} Z_{j} f_{j}$, where $j$ indicates only the biological compartments only of the model, represent the change in fugacity of a POP in a compartment that occurs as a result of a change in volume. These terms perform a similar function to growth dilution terms that represent reductions in fugacity due to increase of the volume of the host organism in some dynamic fugacity models, ${ }^{[27]}$ and digestive concentration terms that represent increases in fugacity of food due to digestion within the gut of an organism. [28]

Models of POP movements in the environment often use fugacity correction terms with constant rates of growth or digestion, and provide reasonable representations of the effects of these processes in fugacity models of large, monotonically growing individual organisms such as fish. However, these terms are not appropriate for plankton population models as these systems are highly dynamic over a seasonal cycle, with periods of relative stasis over winter interspersed with short periods of rapid growth or mortality. Further, as indicated by equation (27), dilution or concentration terms based on constant rates cannot conserve mass, a fundamental property of any model seeking to simulate the movement of POPs in the environment.

We also need to recognise that the volume correction terms operate differently for phytoplankton, zooplankton and detritus. Growth dilution in phytoplankton occurs at constant POP mass, as we assume that the food source (inorganic nutrient) is free of POPs. Loss processes in contrast occur at constant POP concentration, as phytoplankton consumed by grazers, or that die naturally, remove their burden of POP from the population. The fugacity of the phytoplankton population is given by: 


$$
\begin{aligned}
V_{P} Z_{P} \frac{d f_{P}}{d t} & =D_{P W}\left(f_{W}-f_{P}\right)-f_{P} \rho_{P} Z_{P} \varphi P Z-f_{P} \rho_{P} Z_{P} \sigma_{P} P \\
& -f_{P} \rho_{P} Z_{P} \frac{d P}{d t}-f_{P} \rho_{P} P \frac{d Z_{P}}{d t}
\end{aligned},
$$

where $D_{P W}\left(f_{W}-f_{P}\right)$ represents diffusive exchange of POP with the water, $f_{P} \rho_{P} Z_{P} \varphi P Z$ represents the loss of POP from the phytoplankton population due to grazing by zooplankton, $f_{P} \rho_{P} Z_{P} \sigma_{P} P$ represents loss due to mortality, $f_{P} \rho_{P} Z_{P} \frac{d P}{d t}$ is the volume correction term required by conservation of mass (equation (27)), and $f_{P} \rho_{P} P \frac{d Z_{P}}{d t}$ is a temperature correction term (see Supplementary Material for definitions and further details).

The implications of the different processes become clear when we expand the volume correction term. That is, we replace $\frac{d P}{d t}$ with the individual process terms for growth $\left(\mu \frac{N}{N+\kappa} P\right)$, grazing $(\varphi P Z)$ and mortality $\left(\sigma_{P} P\right)$ of phytoplankton from the ecosystem sub-model (equation (9)) to give equation (5) . We observe that the grazing and mortality loss terms cancel out of equation (28) leaving only the growth dilution term $f_{P} \rho_{P} Z_{P}\left(\mu \frac{N}{N+\kappa} P\right)$. This continually reduces $f_{P}$, and hence concentration, to compensate for the continually growing phytoplankton to keep the phytoplankton POP mass constant with respect to growth. The loss terms reduce the mass of POP in the phytoplankton population by reducing the volume of phytoplankton $\left(V_{P}\right)$, but do not affect the concentration of POP $\left(Z_{P} f_{P}\right)$ in the phytoplankton.

The processes affecting the fugacity of the zooplankton (equation (29)) include diffusive exchange with water $\left(D_{Z W}\left(f_{W}-f_{Z}\right)\right)$, growth fuelled by grazing on phytoplankton $\left(f_{P} \rho_{P} Z_{P} \varphi P Z\right)$, excretion of respiration products $\left(f_{Z} \rho_{Z} Z_{Z} \varphi \psi P Z\right)$, 
natural mortality $\left(f_{Z} \rho_{Z} Z_{Z} \sigma_{Z} Z\right)$, a volume correction term $\left(f_{Z} \rho_{Z} Z_{Z} \frac{d Z}{d t}\right)$, and a temperature correction term $\left(f_{Z} \rho_{Z} Z \frac{d Z_{Z}}{d t}\right)$ :

$$
\begin{aligned}
V_{Z} Z_{Z} \frac{d f_{Z}}{d t} & =D_{Z W}\left(f_{W}-f_{Z}\right)+f_{P} \rho_{P} Z_{P} \varphi P Z-f_{Z} \rho_{Z} Z_{Z} \varphi \psi P Z-f_{Z} \rho_{Z} Z_{Z} \sigma_{Z} Z \\
& -f_{Z} \rho_{Z} Z_{Z} \frac{d Z}{d t}-f_{Z} \rho_{Z} Z \frac{d Z_{Z}}{d t}
\end{aligned}
$$

Replacing $\frac{d Z}{d t}$ with its component terms of growth $(\varphi P Z)$, respiration $(\varphi \psi P Z)$ and mortality $\left(\sigma_{Z} Z\right)$ of zooplankton (equation (10)) gives equation (6). The zooplankton population is different to the phytoplankton population because the food that zooplankton use to fuel their growth contains POP, therefore as they continually feed the growth dilution of POP is offset by an increase of mass of POP due to its intake in the food. This is reflected in equation (6) as the loss processes cancel, and we are left with a growth dilution term $\left(f_{P} \rho_{P} Z_{P}-f_{Z} \rho_{Z} Z_{Z}\right) \varphi P Z$ that adjusts $f_{Z}$ proportional to the relative concentrations of POPs in the zooplankton and its food. However, the loss terms function in the same way as for phytoplankton and reduce the mass of POP in the zooplankton population by reducing the volume of the zooplankton $\left(V_{Z}\right)$ while leaving the concentration $\left(Z_{Z} f_{Z}\right)$ constant.

The fugacity of detritus (equation (30)) is controlled by diffusive exchange with water $\left(D_{D W}(1-\omega)\left(f_{W}-f_{D}\right)\right)$, diffusive exchange with sediment via molecular diffusion through water-filled pore spaces $\left(D_{D S} \omega\left(f_{S}-f_{D}\right)\right)$, growth due to accumulation of material from phytoplankton $\left(f_{P} \rho_{P} Z_{P} \sigma_{P} P\right)$ and zooplankton $\left(f_{Z} \rho_{Z} Z_{Z} \varphi \psi P Z+f_{Z} \rho_{Z} Z_{Z} \sigma_{Z} Z\right)$, a volume correction term $\left(f_{D} \rho_{D} Z_{D} \frac{d D}{d t}\right)$, and a temperature correction term $\left(f_{D} \rho_{D} D \frac{d Z_{D}}{d t}\right)$ :

$$
\begin{aligned}
V_{D} Z_{D} \frac{d f_{D}}{d t}= & D_{D W}(1-\omega)\left(f_{W}-f_{D}\right)+D_{D S} \omega\left(f_{S}-f_{D}\right)+f_{Z} \rho_{Z} Z_{Z} \varphi \psi P Z \\
& +f_{P} \rho_{P} Z_{P} \sigma_{P} P+f_{Z} \rho_{Z} Z_{Z} \sigma_{Z} Z-f_{D} \rho_{D} Z_{D} \frac{d D}{d t}-f_{D} \rho_{D} D \frac{d Z_{D}}{d t}
\end{aligned}
$$


Detritus interaction with the sediment through deposition and resuspension is included in the model, although there is little data available of the nature of this interaction in the polar oceans. Detrital deposition can be addressed similarly to suspended sediment by using a particle deposition velocity, ${ }^{[11]}$ however, in the absence of detritus-specific data we introduce a dimensionless location dependent parameter $\omega$ that represents the proportion of detritus in contact with sediment analogously to Patwa et al.[29] The fugacity equations for detritus and water therefore include terms $(1-\omega) V_{D}$ to represent diffusive exchange between these compartments, and the detritus and sediment fugacity equations include terms $\omega V_{D}$. The ecosystem model assumes that remineralisation of the proportion of detritus suspended in the water column proceeds at the same rate as remineralisation of the proportion of detritus that is in contact with the sediment and $\omega$ does not appear in these equations.

Replacing $\frac{d D}{d t}$ with its component terms of growth from phytoplankton and zooplankton mortality $\left(\sigma_{P} P+\sigma_{Z} Z\right)$, and zooplankton respiration ( $\left.\varphi \psi P Z\right)$, and loss from remineralisation ( $v D$ ) (equation (11)) gives equation (7). The growth dilution terms $\left(\left(f_{P} \rho_{P} Z_{P}-f_{D} \rho_{D} Z_{D}\right) \sigma_{P} P\right.$ and $\left.\left(f_{Z} \rho_{Z} Z_{Z}-f_{D} \rho_{D} Z_{D}\right)\left(\varphi \psi P Z+\sigma_{Z} Z\right)\right)$ again reflect the fact that the "food" for detritus contains POPs, and therefore growth dilution occurs if the fugacity of POPs in the food is less than in the detritus, and mass accumulation occurs otherwise. The loss of detritus occurs as a result of remineralisation and there is no physical transport of POP associated with this process. The loss term $f_{D} \rho_{D} Z_{D} v D$ therefore reflects that loss of detritus mass causes an increase in the concentration of POP in detritus but no change in POP mass, and offsets changes in mass of POP in the detritus compartment due to changes in detritus volume $\left(V_{D}\right)$.

The enforcement of conservation of mass on the dynamic coupled fugacity model provides significant improvements to the process representations used in models that have constant growth dilution or food concentration factors. This approach also has the advantage of explicitly representing how the 
fundamentally different food web processes (uptake of inorganic nutrient, consumption of food containing POPs, excretion and mortality, and remineralisation) may affect the fugacity of the associated compartments.

\section{Methods}

\section{Estimation of plankton HCB rate constants}

The uptake rate constants for phytoplankton were obtained by interpolating rate constants measured for polychlorinated biphenyls (PCBs) by Dachs et al.[30] We plotted the rate constants for these compounds against their log Kow values and interpolated with the log Kow value of HCB to derive initial estimates of phytoplankton rate constants. We used a similar approach to estimate uptake and depuration rate constants for zooplankton, based on the measured data of Berrojalbiz et al. [31] which focussed on polycyclic aromatic hydrocarbons (PAHs). This provides only a very approximate estimate, however, this is the only published zooplankton data we are aware of that is useful for this purpose.

The ratio of uptake and depuration rate constants for a POP in an organism should equal the ratio of the $\mathrm{Z}$ values, and this was not the case for the values estimated from the data. Therefore, we employed uptake rate constants ( $k_{P U}$ and $k_{\mathrm{ZU}}$ ) for phytoplankton and zooplankton obtained by interpolation as above, and assumed $k_{P U} V_{P} Z_{W}=k_{P D} V_{P} Z_{P}$ and $k_{Z U} V_{Z} Z_{W}=k_{Z D} V_{Z} Z_{Z}$.

\section{Seasonal Forcing}

The growth rate of the phytoplankton in the ecosystem sub-model was varied as a result of seasonal changes in the sea surface photosynthetically active radiation (PAR), the depth of the surface ocean mixed layer (MLD) and sea surface temperature (SST) measured in an area of the Southern Ocean near the Antarctic coast $\left(60-65^{\circ} \mathrm{S}, 125-140^{\circ} \mathrm{E}\right)$. The relationships used to model the effect of 
changes in the light field and temperature on phytoplankton growth rate are discussed in the Supplementary Material. The seasonal forcing of PAR was derived from a climatology measured by the Sea-viewing Wide-Field-of-View Sensor (SeaWiFS); ${ }^{[32]}$ the seasonal forcing of MLD was obtained from the World Oceanographic Atlas 1998 (WOA98); ${ }^{[33]}$ and the seasonal forcing of SST was obtained from a climatology measured by AVHRR.[34] The SST data and monthly mean air temperatures, sourced from a thirty year archive measured at the Dumont D'urville base ${ }^{[35]}$ located just south of the study region $\left(66^{0} 53^{\prime} \mathrm{S}, 140^{0}\right.$ 30 ' E), were used to correct the fugacity capacities of the compartments of the fugacity sub-model.

\section{Temperature Correction of Fugacity Capacities}

The physical-chemical properties of HCB were corrected to reflect seasonal changes in temperature for the study region using the Van't Hoff expression. ${ }^{[36]}$ The Van't Hoff expression relates a parameter $(X)$ at a specific temperature $(T)$ to a reference value $\left(X_{R}\right)$ at a reference temperature $\left(T_{R}\right)$ using the change in enthalpy $\left(\Delta H_{X}\right)$ or change in internal energy $\left(\Delta U_{X}\right):[36]$

$$
X(T)=X_{R}\left(T_{R}\right) e^{\frac{-\Delta U_{X}}{R}\left(\frac{1}{T}-\frac{1}{T_{R}}\right)}
$$

The Henry's law constant $(H)$, the octanol/water partition coefficient $\left(K_{O W}\right)$ and the sub-cooled liquid vapour pressure $\left(P_{l}^{s}\right)$ were corrected for temperature using a reference temperature $\left(T_{R}\right)$ of $298 \mathrm{~K}$ and the internal phase transfer energies of HCB as described by Shen and Wania. ${ }^{[37]}$ These corrected values were used to calculate seasonal climatologies of temperature-dependent fugacity capacities as described in Table 2.

Dynamic temperature correction requires the inclusion of a $\frac{d Z_{i}}{d t}$ correction term into each fugacity equation, as discussed above. The temperature data were used with equation (31) to generate a seasonal climatology of the fugacity capacity of each compartment. We then numerically fitted a cubic spline to each time series 
and differentiated the spline to give a time series of fugacity capacity correction terms for each compartment. This allowed us to use an adaptive step size integration routine that permitted enforcement of our conservation of mass criterion to machine epsilon. No dynamic correction was made to the fugacity of aerosols as there is no aerosol fugacity equation in this model to apply the correction to. The very low concentrations of aerosols over the Southern Ocean [38] indicates this approximation will have little effect on the model.

We note also that the seasonal variation in water temperature is much smaller than, and out of phase with, the seasonal variation in air temperature in the model environment. We address this difference in air and water phase temperature, and the subsequent effect on air-water movement of POPs after Wania and Mackay ${ }^{[14]}$ by separating the overall air-water transport parameter $\left(D_{A W}\right)$ into phase specific values with temperature dependent $\mathrm{Z}$ values employed as appropriate.

\section{Sensitivity Analysis}

Sensitivity analysis (SA) assesses the degree of variation in the output of a mathematical model with respect to changes in the input values [23] and identifies the most important model parameters and processes. ${ }^{[39]}$ Ciavatta et al. ${ }^{[39]}$ used the Morris Method [40] to analyse the sensitivity of a steady state mass-balance food-web bioaccumulation model in a parameter space that they constructed by applying a variation of $\pm 30 \%$ of measured parameter values. The Morris Method [40] is an efficient SA method that calculates first-order effects $\left(F_{1 i}\right)$, the effects of individual parameters $\left(P_{j}\right)$ in isolation on the metric $\left(M_{i}\right)$ of interest:

$$
F_{1 i}=\frac{\partial M_{i}}{\partial P_{j}} .
$$

We used the New Morris Method, an extension of the Morris Method, which calculates both first and second order effects.[23,41] Second-order effects are calculated from the effects of interactions between two parameters $\left(P_{j}, P_{k}\right)$ on a model output $\left(M_{i}\right)$ of interest: 


$$
F_{2 i}=\frac{\partial M_{i}^{2}}{\partial P_{j} \partial P_{k}}
$$

The SA used the steady state fugacity equations (see Supplementary Material) and the biomagnification factor (BMF) of the food web as the sensitivity metrics $\left(M_{i}\right)$ to test the importance of 30 model parameters. The BMF is defined as the ratio of the zooplankton and phytoplankton concentrations at steady state:

$$
B M F=\frac{f_{Z}^{*} Z_{Z}}{f_{P}^{*} Z_{P}} .
$$

We have assumed that phytoplankton and zooplankton have identical fugacity capacities, as we only model the lipid fraction of the populations; therefore, in this case the biomagnification factor is effectively a ratio of the fugacities.

The unforced steady state fugacities were used as metrics as comprehensive time series measurements of POPs in the Antarctic environment are not available. This is not an optimal approach, but has the advantage that it reduced the computational load of the sensitivity analysis by several orders of magnitude. It provided a useful estimate of the dynamics of the forced model as the steady state fugacities of the unforced model equal the average fugacities of the forced model.[42] The steady state fugacities were calculated at average environmental conditions of air and water temperature, so the temperature independent POP transport parameters $k_{P U}, k_{Z U}, k_{V}, k_{T}$ were considered in the sensitivity analysis rather than their temperature-dependent equivalents. As the steady state fugacities represent the partitioning of POP between the model compartments at steady state, these fugacity metrics were calculated as a proportion:

$$
M_{i}=\frac{f_{i}^{*}}{f_{A}^{*}+f_{W}^{*}+f_{S}^{*}+f_{P}^{*}+f_{Z}^{*}+f_{D}^{*}} .
$$

The steady state relative fugacity metric $\left(M_{i}\right)$ therefore represents the influence of the parameters on the relative proportions of HCB that are partitioned into the various physical and biological compartments at steady state.

The parameter space for the sensitivity analysis was defined as $\pm 50 \%$ of the default values of the model parameters selected for the analysis (Table 1). We 
consider only the 30 most important of the 435 two-factor effects, according to the combined importance $(I)$ :

$$
I=\sum_{i} \frac{M_{i}}{\bar{M}_{i}}
$$

where $\bar{M}_{i}$ is the arithmetic average of the $M_{i}$ and $i=F_{1 A}, F_{1 W}, F_{1 S}, F_{1 P}, F_{1 Z}, F_{1 D}, B M F$.

\section{Model Calibration}

Parameter values for ecosystem models are notoriously poorly constrained, and values are often only available for species other than those being modelled measured at opportune times at locations with very different environments from the study site. ${ }^{43]}$ A further problem is that generally only a few parameter values are reported for any ecosystem, and ecosystem models therefore often use values measured from very different systems. This means that parameter values reported in the literature are generally often only useful as a guide to the appropriate values, as ecosystems function as systems, and it is often the relative magnitudes of, for example, growth and mortality terms that are important, not their absolute magnitudes. The initial values for the NPZD model parameters, obtained from values reported in the literature as indicated in Table 1, were therefore used as starting values to calibrate the NPZD model to reproduce observed plankton dynamics in the study area.

The model was calibrated to in a two-stage process. First the forced ecosystem model was calibrated to reproduce an eight-year climatology of surface ocean chlorophyll- $a$ concentrations measured by the SeaWiFS satellite sensor; ${ }^{[32]}$ in an area of the Southern Ocean near the Antarctic coast $\left(60-65^{\circ} \mathrm{S}, 125-140^{\circ} \mathrm{E}\right)$. The satellite data ( $\mathrm{mgChl} \mathrm{m}{ }^{-3}$ ) was converted to the equivalent of the model output of phytoplankton biomass $\left(\mathrm{mgN} \mathrm{m}^{-3}\right)$ using Redfield ratios: a nitrogen to carbon ratio of 0.175 and a carbon to chlorophyll ratio of $50 .{ }^{[44]}$ The calibrated ecosystem parameter values are given in Table 1, and the calibrated model seasonal dynamics are shown with the SeaWiFS chlorophyll data in Figure 2. 
The calibrated ecosystem parameter values were then used for the calibration of the fugacity sub-model. Measured concentrations of HCB in each air, water, sediment, phytoplankton and zooplankton (with the exception of detritus due to a lack of data), reported in recently published literature (Table 3) suggested that a total HCB mass of $5 \times 10^{-7}$ moles was appropriate for the defined model domain. The calibration of the fugacity sub-model was initiated by assuming that the closed system contained a mass of $5 \times 10^{-7}$ moles of HCB. ${ }^{[45]}$ The steady state HCB fugacity in each compartment was calculated and the relative magnitudes of the fugacities in each compartment $\left(f_{i}^{\prime}\right)$ were then calculated:

$$
f_{i}^{\prime}=\frac{f_{i}^{*}}{f_{A}^{*}+f_{W}^{*}+f_{S}^{*}+f_{P}^{*}+f_{Z}^{*}+f_{D}^{*}},
$$

and used to calculate an equivalent un-scaled mass of HCB:

$$
H C B_{U S}=V_{A} Z_{A} f_{A}^{\prime}+V_{W} Z_{W} f_{W}^{\prime}+V_{S} Z_{S} f_{S}^{\prime}+V_{P} Z_{P} f_{P}^{\prime}+V_{Z} Z_{Z} f_{Z}^{\prime}+V_{D} Z_{D} f_{D}^{\prime} .
$$

A scaling factor $(S)$ was then calculated:

$$
S=\frac{H C B_{U S}}{5 \times 10^{-7}},
$$

and applied to the unscaled fugacities to obtain the steady state fugacities $\left(\hat{f}_{i}\right)$ assuming a total HCB mass of $5 \times 10^{-7}$ moles:

$$
\hat{f}_{i}=S f_{i}^{\prime} .
$$

The scaled steady state HCB fugacity of each compartment therefore represented what proportion of the total $5 \times 10^{-7}$ moles of HCB it contained at the average sea surface temperature $(273.5 \mathrm{~K})$ of the study region. The fugacities obtained were sufficiently close to the reported values (Table 3 ) that the fugacity model parameters were not varied from the literature values.

\section{Dynamic simulations}

The seasonally-forced model equations were integrated over a multi-year time span until a repeating annual cycle was obtained. This ensured that the initial conditions did not affect the results, as we were interested in a 'typical' annual 
cycle rather than a response to a perturbation (which will be addressed in future work). The seasonal forcing of PAR, MLD and SST from SeaWiFS, WOA98 and AVHRR used for the NPZD sub-model calibration, plus the air temperature climatology for Dumont d'Urville, were used to dynamically force the coupled model simulations. We also ran simulations in which the fugacity capacities of the compartments were not corrected for variations in temperature in order to be able to differentiate POP movements that resulted from ecosystem dynamics from those associated with changes in temperature. The results of these simulations are not explicitly shown, but are the basis for our attribution of HCB fluxes to ecosystem processes or temperature variation.

\section{Results \& Discussion}

\section{Sensitivity Analysis}

The sensitivity analysis of the first- and second-order effects on the steady state fugacities (Figures 3 and 4) reveal that several physical and biological parameters are important determinants of the long term partitioning of HCB in the modelled Antarctic plankton food web. Many of the results of the SA are consistent with expectations, suggesting that the model has incorporated the processes controlling fugacity correctly. For example, the fugacity capacities of water $\left(Z_{W}\right)$ and atmospheric aerosols $\left(Z_{x}\right)$ and the mass transfer coefficient for air/water exchange of $\operatorname{HCB}\left(k_{V}\right)$ are the most important determinants of the steady state relative fugacity of the air $\left(f_{A}^{*}\right)$ (Figure 3a). The interesting results from the SA are those that indicate unexpected influences on the steady state relative fugacities or unexpected linkages between the physical and biological components of the model. For example, the result that the rates of bottom sediment resuspension and deposition $\left(U_{R}\right.$ and $\left.U_{D}\right)$ are also important determinants of the steady state relative fugacity of the air is unexpected, and it is aspects of the SA such as these that we will focus on. 


\section{First Order Effects}

The first order effects indicate that different processes control the steady state fugacities of HCB in the biological and physical compartments. The resuspension and deposition of bottom sediments $\left(U_{R}\right.$ and $\left.U_{D}\right)$ are major influences on the fugacity of all compartments other than phytoplankton and zooplankton, which are primarily determined by the zooplankton parameters $\varphi$ (grazing rate), $\psi$ (assimilation efficiency) and $\sigma_{z}$ (mortality). Secondary influences on all compartments are the fugacity capacities of water and sediment $\left(Z_{W}\right.$ and $\left.Z_{S}\right)$, suggesting the importance of mobilising HCB from the sediments into the water and thence into the ecosystem. However, we note that detritus, a biological compartment, has almost identical sensitivities to sediment, and while their HCB fugacities are dominated by the resuspension and deposition of bottom sediments they are also sensitive to biological parameters. The coupling between the physical and biological systems is further evident in the sensitivities of the sediment (Fig 3(c)) and detritus (Fig 3(f)), where additionally air/water $\left(k_{V}\right)$ and sediment/water $\left(k_{T}\right)$ processes are important. We note, however, that the fraction of detritus that is in contact with the sediment $(\omega)$ is not an important influence on the steady state fugacities.

The zooplankton assimilation efficiency and mortality rate, with the zooplankton grazing rate, define the steady state of the phytoplankton population (see Supplementary Material), suggesting that the seasonal dynamics of the phytoplankton population, which reach their greatest amplitude in polar waters, could generate seasonal changes in the HCB fugacities of the physical compartments. Dachs et al. ${ }^{[17]}$ similarly found that air-water exchange of POPs was influenced by phytoplankton parameters in a dynamic model that coupled an air-water system to phytoplankton uptake. 


\section{Second Order Effects}

Many of the effects on the steady state relative fugacities of the interactions of the 30 most important parameter combinations overall (Figure 4) may be expected from the first-order effects (Figure 3), for example the influence of the combination of the resuspension and deposition rates of bottom sediments on the air, water, sediment and detritus fugacities (Figure 4 (a, b, c and f)). Similarly, the importance of combinations of the zooplankton grazing, assimilation and mortality parameters on phytoplankton and zooplankton fugacities is not surprising (Figure $4(\mathrm{~d}$ and e)). This discussion focuses on the effect of the parameter combinations that most affect overall fugacities, as defined by equation (36), on the fugacities of the individual phases.

Figure 4 reveals that there are few couplings between the physical and biological systems as important parameter combinations are essentially grouped into combinations of biological parameters or combinations of physical parameters. However, the phytoplankton and zooplankton fugacities (Figure 4 ( $\mathrm{d}$ and e)), and to a lesser extent the water and detritus fugacities (Figure 4 ( $c$ and f)) reveal subtle couplings between biological and physical parameters. These interactions include the zooplankton grazing rate with sediment resuspension and deposition, and zooplankton assimilation efficiency and mortality with sediment deposition.

As for the first order effects, the sensitivities of sediment and detritus (Figure 4 (c and f)) are virtually identical, and include sensitivities to both physical and biological processes. This suggests that the flux of material through the detritus compartment, including the interaction between detritus and zooplankton, the major source of detrital material in this model, may be an important determinant of the partitioning of HCB in the physical environment. The efficacy of models of HCB movement through the environment might therefore be improved by more comprehensive field measurements of POPs in detritus. This may be especially relevant to polar environments, where the intra-annual variation in phytoplankton biomass can be several orders of magnitude. 
The first order SA for the food web biomagnification factor (Figure 5, left panel) clearly identified the ecosystem parameters zooplankton grazing, assimilation efficiency and mortality, which determine the throughput of material by zooplankton and also control the steady state abundance of phytoplankton, as the most important determinants of biomagnification in zooplankton. The lipid fractions of the plankton $\left(\xi_{P}\right.$ and $\xi_{Z}$ ) were the next most significant influences on the BMF, followed by the mass-volume conversion ratios of the phytoplankton and zooplankton $\left(\gamma_{P}\right.$ and $\left.\gamma_{Z}\right)$ and the rate constants for diffusive uptake into phytoplankton and zooplankton ( $k_{p u}$ and $k_{z u}$ ). The values of all these parameters are very poorly constrained, suggesting that any model predictions of BMFs in food webs should be examined very carefully for their assumptions regarding these parameters.

Perhaps the most interesting results are that this SA indicated that the sensitivity of the BMF was more sensitive to ecosystem parameters, and in particular the zooplankton characteristics $\varphi, \psi$ and $\sigma_{z}$ that define the steady state of the phytoplankton population, than any of the physical parameters. This result is interesting when compared to the results of Kelly et al. ${ }^{[46]}$ who predicted BMFs in water respiring organisms solely from $K_{O W}$. This parameter does not appear explicitly in the SA but its influence is included in the fugacity capacities of the biota $\left(Z_{P}\right.$ and $\left.Z_{Z}\right)$ that are included in the SA. These parameters have little effect on BMF (Figure 5).

This sensitivity analysis and the results reported by Kelly et al. [46] are both based on the steady states of dynamic fugacity models. The major difference between these models lies in the detail of representation of key processes. In this model we have focussed on the dynamics of the food web and how that affects the movement of POPs in the environment. We have enforced system-scale concepts 
such as interactions between trophic levels, population dynamics and conservation of mass, but have crude representations of processes such as gastrointestinal uptake. In contrast, Kelly et al. [46] use more detailed representations of processes such as gastrointestinal uptake, but have uniform representations of organism growth, do not explicitly model interactions between trophic levels, and do not simulate population dynamics. However, perhaps the most important difference between the models is that the Kelly et al. [46] model does not explicitly include detritus, which this analysis suggests is a significant coupling between the physical and biological systems. The contrast in these approaches and results provides useful directions for future research to resolve these differences, especially in light of the variation that results from the seasonality of the environment.

\section{Dynamic Simulation Results}

Seasonal variations in irradiance and temperature ${ }^{[47]}$ generate significant annual cycles in plankton populations in Antarctica (Figure 2). The simulated phytoplankton population peaks in early summer, ${ }^{[48]}$ consistent with satellite observations, and although the zooplankton population begins to grow as the phytoplankton population increases, there is a significant temporal lag before the zooplankton population reaches its maximum biomass. Detritus also evidences an annual cycle with a peak lagging by a few days the peak in zooplankton biomass, confirming the zooplankton respiration and excretion as the major sources of detritus in the model.

The seasonal cycle of the plankton biomass (Figure 2) induces a seasonal cycle in the fugacity of HCB of each phase in additional to seasonal variations of fugacity of both biological and physical compartments due to the temperature dependence of the fugacity capacities (Figure 6). The amplitude of the cycling induced by the biology is much less than one percent of the mean fugacity in the air and sediment compartments (Figure $6 \mathrm{a}, \mathrm{c}$ ), 1-2\% in the water and detritus compartments (Figure $6 \mathrm{~b}, \mathrm{f}$ ), but $50-60 \%$ in the phytoplankton and zooplankton 
compartments (Figure $6 \mathrm{~d}, \mathrm{e}$ ). The variations in fugacity induced by the temperature variations are approximately 5\% in air, 30\% in water and detritus, $50 \%$ in sediment, and around $20 \%$ in phytoplankton and zooplankton. The intraannual variations in fugacity in Figure 6 are therefore confounded by the effect of temperature variations and biomass variations, with temperature being the major driver of seasonal variation of fugacity in the physical compartments and ecosystem dynamics the major driver in the biological compartments. Detritus, although of biological origin, has seasonal variations in fugacity more like the physical phases of sediment and water than the biological phases of the plankton.

The HCB fugacity of the phytoplankton population reaches a peak in late summer (Figure $6 \mathrm{~d}$ ) that lags behind the population reaching its highest biomass (Figure 2). The mass of HCB in the phytoplankton population (Figure $7 \mathrm{~d}$ ) peaks between these maxima. There is a second phytoplankton HCB fugacity peak in late winter that corresponds to the minimum phytoplankton biomass resulting in the minimum HCB mass in phytoplankton occurring in mid-autumn. The second phytoplankton HCB fugacity peak occurs when its rate of diffusive uptake of HCB is at a minimum (Figure $8 \mathrm{c}$ ), suggesting that although zooplankton grazing is also near its minimum (Figures 2 and $9 \mathrm{~b}$ ) it is sufficient to affect the fugacity of HCB in the very small phytoplankton population.

The concentrations of HCB in each compartment scale linearly with fugacity (equation (1)), so the seasonal variations in concentration of HCB in each phase are identical to those of fugacity (Figure 6). The very high fugacity capacities of the biological phases ensure that they have the highest concentrations of HCB, with mean annual concentrations of between one and two orders of magnitude greater than that of the sediment, the physical compartment with the highest concentration of HCB.

The model predicts that detritus will have the highest concentration of HCB, but because of its very low mass it does not contain as much HCB mass as the physical compartments (Figure 7). However, detritus usually contains more HCB 
mass than either of the plankton compartments. This result is interesting because detritus is rarely represented as a separate dynamic compartment in models simulating the movement of POPs through ecosystems. Planktonic detritus is often included in a "suspended solids" compartment that is comprised of material with different origins and very different properties, and is not dynamically linked to the ecosystem that generates it.

The seasonal variation of the fugacity of detritus (Figure 6f) suggests that it behaves more like a physical compartment than a biological one as it has virtually identical HCB fugacity dynamics to the water and sediment phases. However, the seasonal variation of the mass of HCB in detritus (Figure $7 f$ ) suggests that it behaves more like a biological compartment than a physical one, and shares an almost identical seasonal dynamic of the mass of HCB with zooplankton. This suggests a key role for detritus in the coupling of HCB in the physical and biological phases, with the distribution of HCB in the environment somewhat counter-intuitively being controlled by the depuration of HCB from the biota to the water via detritus, rather than the uptake side.

The distribution of HCB mass predicted by the model reveals the coupling between the seasonal variations in biomass and fugacities, with phytoplankton, zooplankton and detritus showing very clear seasonal cycles of HCB mass. The air, water and sediment phases have seasonal cycles with amplitudes of less than $2 \%$ of the average mass of HCB they contain. In contrast, the mass of HCB in phytoplankton (Figure 7d) has a seasonal variation approximately $125 \%$ of its average value, but the seasonal cycles evident in the detritus and zooplankton have much larger amplitudes, approximately $300-350 \%$ of their average HCB mass. The temporal evolution of HCB mass in zooplankton and detritus is almost identical, with the detritus peak lagging behind the zooplankton peak by approximately 10 days. Figures 2 and 7 (d-f) clearly show the increase in mass in phytoplankton as a result of its growth and subsequent diffusive uptake of HCB occurring first, the subsequent increase of HCB in zooplankton through diffusive uptake and the transfer of mass by grazing, and the rapid transfer of HCB from zooplankton to detritus through zooplankton respiration and mortality. 
The rates of movement of HCB mass as a result of diffusive exchange with water (Figure 8) clearly show the effect of the plankton on the movement of HCB mass between the phases and the significant role of detritus in determining the diffusive distribution of HCB within the environment. The diffusive fluxes from the water to the air and sediment (Figure $8(a, b)$ ) are almost entirely due to seasonal variations in the fugacity capacities that result from changes in temperature. The austral spring phytoplankton bloom that commences around Julian day 250 (Figure 2) initiates a diffusive movement of HCB mass from the water into the phytoplankton that peaks around Julian day 350 (Figure 8c). Although the phytoplankton population falls to quite low biomass during the austral winter, Figure 8c reveals that the phytoplankton population acts as a constant sink of HCB from the water.

The zooplankton bloom that results from the increased availability of phytoplankton for food initiates around Julian day 350 and peaks around Julian day 65 (Figure 2). The dramatic increase in zooplankton biomass initiates a diffusive transfer of HCB mass from the water into the zooplankton that peaks around Julian day 65 (Figure 8d). As zooplankton also acquire HCB through consumption of phytoplankton their diffusive uptake of HCB is lower than that of phytoplankton, but the reduction in their fugacity as a result of their rapid growth results in their acting as a sink of HCB from the water during the bloom. The zooplankton population falls to very low levels during the austral winter as their food supply is reduced; consequently the diffusive uptake from water to zooplankton reduces to almost zero, but neither plankton population ever acts as a diffusive source of HCB to the water.

The largest diffusive transport of HCB mass in the model occurs between the water and detritus (Figure 8e), with maximum flux values at least an order of magnitude larger than the diffusive exchange between the physical compartments, and two - three orders of magnitude larger than the biological compartments. Detritus exchange with sediment is several orders of magnitude lower than its exchange with water due to the tortuous path approximation used 
for this process. ${ }^{[12]}$ Only sediment and detritus act as both diffusive sources and sinks of HCB mass for the water (Figure 8b, e). The sediment-water flux is driven by changes in temperature, while the detritus-water flux, which is two orders of magnitude greater than between sediment-water flux, is driven by ecosystem dynamics. There is also a very small diffusive exchange of HCB between the sediment and detritus (Figure 8f).

The detritus mass peaks at about Julian day 70 (Figure 2), only a few days after the zooplankton biomass peaks. The detritus initially acts a sink for HCB mass from the water as its mass increases, with the maximum rate of mass transfer occurring around Julian day 33. At approximately the time the maximum detritus mass is achieved (Julian day 70) the HCB fugacities of the water and detritus have equalised, and thereafter the remineralisation of the detritus mass results in detritus acting as a source of HCB to the water until the next plankton bloom. The transition of detritus from major sink to major source occurs relatively rapidly, with an interval of 74 days between the maximum sink (Julian day 33) and the maximum source (Julian day 107). The detritus acts as a slowly reducing source of HCB to the water until Julian day 270 when the detritus mass reaches its minimum prior to receiving new material containing HCB from the new plankton bloom. The equilibration of detritus with sediment occurs later than with water, at about Julian day 110 , but detritus acts as a source of HCB to sediment for longer, up to about Julian day 345 . However the transfer of mass of HCB from detritus to sediment is several orders of magnitude less than the water diffusive processes in the model.

The rates of movement of HCB mass as a result of ecological interactions (Figure 9) are of similar magnitude to the rates of transport in the physical system. The seasonal variations in the individual ecosystem processes (Figure 9 a-d) show peaks in gain and loss processes that correlate with the biomasses of the relevant plankton. The overall movement of HCB mass through the phytoplankton (Figure 9e) reaches a maximum net uptake rate around Julian day 325 that corresponds with the maximum diffusive uptake, and a maximum net loss rate around Julian day 45 associated with the maximum in zooplankton grazing. Similarly, the 
zooplankton population experiences a maximum HCB mass net uptake rate around Julian day 40 associated with the maximum grazing uptake rate that occurs around Julian day 55 and a maximum HCB mass net loss rate around Julian day 80 associated with the maximum diffusive loss that occurs around Julian day 65 (Figure 9f). Apart from these maxima and minima in the rates of HCB mass transfer the physical and biological processes in the plankton approximately balance.

The BMF of zooplankton (Figure 10) clearly shows a seasonal variation of approximately $17 \%$ of its mean value (2.3). The mean BMF achieved by zooplankton differs from the 1.8 suggested for HCB by the Kelly et al model.[46] This is not surprising given that we have used literature values for many parameters in the simulations and have made no attempt to calibrate the model to produce the Kelly et al [46] or any other prediction. The results of the SA of the BMF (Figure 5) suggest that agreement with measured or other predicted values could be readily achieved by manipulating the lipid fractions $\left(\xi_{P}, \xi_{Z}\right)$ and/or mass-volume conversion factors $\left(\gamma_{P}, \gamma_{Z}\right)$ of the plankton. However, the point we wish to emphasise is not that this model can accurately predict the BMF, but that seasonal variation in the zooplankton BMF is indicated. In particular, the zooplankton BMF is sensitive to when it is measured, and measurements made in summer, as they generally are in polar marine environments, may underestimate the maximum BMF.

Finally, our dynamic simulations support observations in field and modelling studies that increasing phytoplankton biomass results in lower than equilibrium POP concentrations in phytoplankton. ${ }^{[30,49]}$ When phytoplankton biomass is high (Figure 2) the concentration of HCB is low (Figure 6), although this is not a simple relationship, as indicated by the correlation coefficient of $r=-0.33$ (measures of statistical significance are irrelevant in this case). However, our results do not support the common assumption that this results in lower amounts of POPs being transported in the food web. Comparison of Figures 2 and 7 reveals that the mass of HCB in the phytoplankton is closely correlated with phytoplankton biomass ( $r=0.94)$. Examination of the fluxes of HCB over 
the seasonal cycle clearly demonstrate that even though the concentration of HCB in phytoplankton may be below equilibrium, the flux of HCB mass into phytoplankton peaks during the phytoplankton bloom (Figure 8c). The reduction in phytoplankton fugacity as a result of growth dilution creates a "fugacity pump" that rapidly draws HCB mass into phytoplankton, confirmed by the $r=0.99$ correlation between phytoplankton biomass and flux of HCB mass into the phytoplankton. The ecosystem fluxes (Figure 9) shows that this influx of HCB is rapidly moved through the ecosystem as the zooplankton population blooms and thence ending up in the detritus about 80 days after the phytoplankton population peak. Our results therefore suggest that low phytoplankton POP concentrations should not be interpreted as indicating that the transport of POPs in the food web is decreased, but that in fact the reverse may hold.

\section{Conclusions}

This paper describes the development of a fully coupled dynamic, mass conservative, plankton food web fugacity model and uses the limited knowledge of HCB in the Antarctic environment to investigate the major processes affecting the distribution of HCB, and by inference other POPs, in that environment. Several unique features distinguish this model from other food web fugacity models. The most fundamental attribute is that the model conserves the mass of both important quantities, limiting nutrient and HCB, within the simulated closed environment. Whilst this property is common in food web models, this is the first dynamic food web fugacity model that conserves the mass of POP. The model is able to do this because it uses dynamic fugacity correction terms derived from the ecosystem sub-model rather than growth dilution constants to compensate for the change in volume of the biota.

The application of the model to simulate the distribution of HCB in the Antarctic environment has generated some interesting insights into the relative importance of the processes involved. The first of these is that food web dynamics can subtly affect the distribution of HCB in the environment, as the 
seasonal variations observed in the plankton populations are also found in the coupled physical compartments. The cycles observed in the physical compartments are mostly driven by variations in temperature, but we note that in order to obtain sufficient satellite data points to calibrate the plankton ecosystem model the simulations were parameterised for a part of the Southern Ocean that has relatively small amplitude phytoplankton population dynamics. The SeaWiFS climatology of satellite chlorophyll- $a$ data reveals that the dynamics of phytoplankton ecosystems closer to the Antarctic coast (and near Arctic coasts) can have seasonal variations with amplitudes an order of magnitude greater than used in this work. This suggests that the "fugacity pumping" of POPs into Antarctic ecosystems by phytoplankton may be an order of magnitude greater than observed in these simulations, generating observable ecosystem-driven seasonal variations of POP concentration in the physical compartments. It is plausible then that plankton ecosystem dynamics may have much more profound effects on the distributions, and the dynamics of the distributions, of POPs in Arctic and Antarctic coastal environments than is evident in this work.

The model simulations also highlight the potential importance of detritus for the distribution of POPs in the environment. The model identifies detritus as a compartment with unique properties that couples the physical and biological systems. Detritus is a product of the plankton ecosystem, and so could be expected to share many of the properties of the other ecosystem compartments. However, the fugacity (and hence concentration) of HCB in detritus is mostly driven by temperature, and overwhelm the seasonal variations in detritus driven by variations in the phytoplankton and zooplankton compartments. In these respects detritus has properties more closely aligned with those of the physical compartments. The mass of HCB in detritus, in contrast, has seasonal variations very similar to those of the plankton, and in particular almost identical to zooplankton, confirming its key role in coupling the systems.

The model also provides an interesting insight into the processes controlling biomagnification in food webs comprised of water-respiring organisms. The SA 
indicates that the BMF for zooplankton is highly sensitive to zooplankton ecosystem parameters, to the plankton mass to volume conversion ratios and the plankton lipid fractions, and to the biophysical parameters associated with diffusive uptake by plankton. It is relatively insensitive to all physical parameters, in contrast to the modelling of Kelly et al. [46] who suggested that biomagnification was primarily a function of the $K_{o w}$ of the POP, and predicted that HCB, with a $\log K_{o w}$ of approximately 5.5, had a biomagnification factor of 1.8 in zooplankton (we obtain an average BMF for zooplankton of 2.3).

Further, the dynamic simulation results reveal that the BMF is influenced by the ecosystem dynamics, exhibiting seasonal variation that results from differences in timing of the seasonal variations in phytoplankton and zooplankton fugacity. This may explain apparently conflicting measurements of BMFs in Antarctic ecosystems, [50-52] although mechanistic models of POPs in food webs typically predict biomagnification.

The modelling reported here contributes to the discussion of POPs in polar environments by predicting that the distribution of HCB in the Antarctic environment has significant seasonal variation driven by the food web dynamics, and that detritus plays a central role in the cycling of POPs in polar environments. The latter observation is particularly interesting in light of recent observations by Clarke and Tyler [53] of the Antarctic krill Euphausia superba nosediving into sediment and actively feeding on the resuspended particulates. This suggests that a useful future modelling scenario could examine the effect that zooplankton grazing on detritus has on the movement of POPs through an ecosystem.

Finally, the explicit application of the principle of conservation of mass in the development of the coupled fugacity model, in addition to formally recognising basic laws and providing computational checks on numerical model solutions, has the advantage of explicitly determining precise forms for the biological fugacity processes. It differentiates process functional forms for growth dilution as a result of consumption of inorganic nutrients that do not contain POPs from 
growth dilution that occurs as a result of consumption of food that does contain POPs. It also differentiates process functional forms for the loss of material due to grazing, that occur at constant concentrations, from remineralisation of organic matter that leads to digestive concentration. These properties provide a firm base for the further development of dynamic ecosystem models to investigate the role of biological systems in determining the movement of POPs in the environment. 


\section{References}

[1] Brown TN, Wania F. Screening Chemicals for the Potential to be Persistent Organic Pollutants: A Case Study of Arctic Contaminants. Environmental Science \& Technology. 2008, 42, 5202 - 9.

[2] UNEP. in United Nations Environmental Program 2001, (Geneva, Switzerland ).

[3] Wania F, Mackay D. The evolution of mass balance models of persistent organic pollutant fate in the environment. Environmental Pollution. 1999, 100, 223 - 40.

[4] Kelly BC, Ikonomou MG, Blair JD, Gobas FAPC. Bioaccumulation behaviour of polybrominated diphenyl ethers (PBDEs) in a Canadian Arctic marine food web. Sci Total Environ. 2008, 401(1-3), 60-72.

[5] Bengtson Nash SM. Persistent Organic Pollutants in Antarctica; Current and Future Research Priorities. Journal of Environmental Monitoring. 2010.

[6] De Laender F, Van Oevelen D, Frantzen S, Middelburg JJ, Soetaert K. Seasonal PCB Bioaccumulation in an Arctic Marine Ecosystem: A Model Analysis Incorporating Lipid Dynamics, Food-Web Productivity and Migration. Environmental Science \& Technology. 2010, 44, 356-61.

[7] Corsolini S, Romeo T, Ademollo N, Greco S, Focardi S. POPs in key species of marine Antarctic ecosystem. Microchemical Journal. 2002, 73(1-2), 187-93.

[8] Bengtson Nash SM, Poulsen AH, Kawaguchi S, Vetter W, Schlabach M. Persistent organohalogen contaminant burdens in Antarctic krill (Euphausia superba) from the eastern Antarctic sector: A baseline study. Science of the Total Environment. 2008, 407, 304-14.

[9] Marchant HJ, Scott FJ, Davidson AT. Eds. Scott FJ, Marchant HJ)2005, (Australian Antarctic Division: Hobart).

[10] Scheringer M, Wania F. in The Handbook of Environmental Chemistry (Ed. Fiedler H)2003, pp. 237-69 (Springer-Verlag: Berlin).

[11] Mackay D. Multimedia Environmental Models. The Fugacity Approach. 2001 (Taylor and Francis: Boca Raton).

[12] Wania F, Breivik K, Persson NJ, McLachlan MS. CoZMo-POP2 A fugacitybased dynamic multi-compartmental mass balance model of the fate of persistent organic pollutants. Environmental Modelling and Software 2006, 21, 868-84.

[13] Mackay D, Arnot JA, Webster E, Reid L. in Ecotoxicology Modeling: Emerging Topics in Ecotoxicology: Principles, approaches and Perspectives 2 2009, pp. 355-75. (Springer).

[14] Wania F, Mackay D. A global distribution model for persistent organic chemcials. The Science of the Total Environment. 1995, 160, 211-32.

[15] Mackay D, Paterson S. Evaluating the Multimedia Fate of Organic Chemicals: A Level III Fugacity Model. Environmental Science \& Technology. 1991, 25, 427-36.

[16] Mackay D, Wania F. Transport of contaminants to the Arctic: partitioning, processes and models. The Science of the Total Environment. 1995, 160, 25-38. 
[17] Dachs J, Eisenreich SJ, J.E. B, Ko F-C, Jeremiason JD. Coupling of Phytoplankton Uptake and Air-Water Exchange of Persistent Organic Pollutants. Environ Sci Technol. 1999, 33, 3653-60.

[18] Franks PJS. NPZ Models of Plankton Dynamics: Their Construction, Coupling to Physics, and Application. Journal of Oceanography. 2002, 58, 379 87.

[19] Edwards AM. Adding detritus to a nutrient-phytoplankton-zooplankton model: a dynamical-systems approach. Journal of Plankton Research. 2001, 23(4), 389-413.

[20] Sverdrup HV. On conditions for the vernal blooming of phytoplankton. Journal Conseil International Exploration du Mer. 1953, 18, 287-95.

[21] Weber K, Goerke H. Persistent organic pollutants (POPs) in antarctic fish: levels, patterns, changes. Chemosphere. 2003, 53(6), 667 - 78.

[22] Fuoco R, Capodaglio G, Muscatello B, Radaeli M. (Ed. Antarctica SAGoECi)2009, pp. 98 (Cambridge).

[23] Campolongo F, Braddock R. The use of graph theory in the sensitivity analysis of the model output: a second order screening method. Reliability Engineering and System Safety. 1999, 64, 1-12.

[24] Hughes L, Webster E, Mackay D. An Evaluative Screening Level Model of the Fate of Organic Chemicals in Sludge-Amended Soils Including Organic Matter Degradation. Soil and Sediment Contamination: An Interational Journal. 2008, 17(6), $564-85$.

[25] Cropp R, Norbury J. Parameterizing plankton functional type models: insights from a dynamical systems perspective. J Plankton Res. 2009, 31, 939-63.

[26] Reynolds C. Ecology of Phytoplankton. 2006 (University of Cambridge: Cambridge).

[27] Ng CA, Gray KA. Tracking bioaccumulation in aquatic organisms: A dynamic model integrating life history characteristics and environmental change. Ecol Model. 2009, 220, 1266-73.

[28] Arnot JA, Gobas FAPC. A food web bioaccumulation model for organic chemicals in aquatic ecosystems. Environ Toxicol Chem. 2004, 23(10), 2343-55.

[29] Patwa Z, Christensen R, Lasenby DC, Webster E, Mackay D. An exploration of the role of mysids in benthis-pelagic coupling and biomagnification using a dynamic bioaccumulation model. Environ Toxicol Chem. 2007, 26(6), 1224-32.

[30] Dachs J, Eisenreich SJ, Hoff RM. Influence of Eutrophication on Air-Water Exchange, Vertical Fluxes, and Phytoplankton Concentrations of Persistent Organic Pollutants. Environmental Science \& Technology. 2000, 34, 1095-102.

[31] Berrojalbiz N, Lacorte S, Calbet A, Saiz E, Barata C, Dachs J. Accumulation and Cycling of Polycyclic Aromatic Hydrocarbons in Zooplankton. Environmental Science \& Technology. 2009, 43, 2295 - 301.

[32] Hooker SB, McClain CR. The Calibration And Validation Of Seawifs Data. Prog Oceanogr. 2000, 45, 427-65.

[33] Levitus S. World Ocean Atlas 19981998 (U.S. Gov. Printing Office: Washington).

[34] Hastings DA, Emery WJ. The Advanced Very High Resolution Radiometer (AVHRR): A Brief Reference Guide. Photogrammetric Engineering and Remote Sensing. 1992, 58(8), 1183-8. 
[35] Stearns CR, Keller LM, Weidner GA, Sievers M. in Antarctic Meteorology and Climatology: Studies based on automatic weather stations Eds. Bromwich DH, Stearns CR)1993, pp. 1-21 (American Geophysical Union: Washington, DC).

[36] Schwarzenbach RP. Environmental Organic Chemistry 2003 (John Wiley \& Sons: Hoboken).

[37] Shen L, Wania F. Compilation, Evaluation, and Selection of PhysicalChemical Property Data for Organochlorine Pesticides. Journal of Chemical \& Engineering Data. 2005, 50, 742-68.

[38] Mahowald NM, Baker AR, Bergametti G, Brooks N, Duce RA, Jickells TD, Kubilay N, Prospero JM, Tegen I. Atmospheric global dust cycle and iron inputs to the ocean. Global Biogeochem Cycles. 2005, 19(GB4025), doi:10.1029/2004GB002402.

[39] Ciavatta S, Lovato T, Ratto M, Pastres R. Global uncertainty and sensitivity analysis of a food-web bioaccumulation model. Environmental Toxicology and Chemistry. 2009, 28(4), 718-32.

[40] Morris MD. Factorial sampling plans for preliminary computational experiments. Technometrics. 1991, 332, 161-74.

[41] Cropp RA, Braddock RD. The New Morris Method: an efficient secondorder screening method. Reliability Engineering and System Safety. 2002, 78(1), 77-83.

[42] Kiorboe T. A Mechanistic Approach to Plankton Ecology. 2008 (Princeton University Press).

[43] Hood RR, Laws EA, Follows MJ, Siegel DA. Modeling and prediction of marine microbial populations in the genomic era. Oceanography. 2007, 20(2), 155-65.

[44] Gabric AJ, Whetton PH, Cropp RA. Dimethylsulphide production in the subantarctic southern ocean under enhanced greenhouse conditions. Tellus. 2001, 53(B), 273-87.

[45] Klánová J, Matykiewiczová N, Máčka Z, Prošek $\mathrm{P}$, Láska $\mathrm{K}$, Klán $\mathrm{P}$. Persistent organic pollutants in soils and sediments from James Ross Island, Antarctica. Environ Pollut. 2008, 152, 416-23.

[46] Kelly BC, Ikonomou MG, Blair JD, Morin AE, Gobas FAPC. Food WebSpecific Biomagnification of Persistent Organic Pollutants. Science. 2007, 317, $236-8$.

[47] Behrenfeld MJ, Halsey KH, Milligan AJ. Evolved physiological responses of phytoplankton to their integrated growth environment. Philosophical Transactions A. 2010, 363, 2687 - 703.

[48] Smith Jr WO, Marra J, Hiscock MR, Barber RT. The seasonal cycle of phytoplankton biomass and primary productivity in the Ross Sea, Antarctica. Deep-Sea Research II. 2000, 47, 3119 - 40.

[49] Larsson P, Andersson A, Broman D, Nordback J, Lundberg E. Persistent organic pollutants (POPs) in pelagic systems. Ambio. 2000, 29(4-5), 202-9.

[50] Chiuchiolo AL, Dickhut RM, Cochran MA, Ducklow HW. Persistent Organic Pollutants at the Base of the Antarctic Marine Food Web. Environmental Science \& Technology. 2004, 38, 3551-7.

[51] Sobek A, Cornelissen G, Tiselius P, Gustafsson Ö. Passive Partitioning of Polychlorinated Biphenyls between Seawater and Zooplankton, a Study Comparing Observed Field Distributions to Equilibrium Sorption Experiments. Environ Sci Technol. 2006, 40, 6703 - 8. 
[52] Sobek A, McLachlan M, Borga K, Asplund L, Lundstedt-Enkel K, Polder A, Gustafsson O. A comparison of PCB bioaccumulation factors between an arctic and a temperate marine food web. Sci Total Environ. 2010, 408(13), 2753-60.

[53] Clarke A, Tyler PA. Adult Antarctic Krill Feeding at Abyssal Depths. Current Biology. 2008, 18, 282-5.

[54] Gabric AJ, Cropp R, Hirst T, Marchant H. The sensitivity of dimethyl sulfide production to simulated climate change in the Eastern Antarctic Southern Ocean. Tellus, Series B: Chemical and Physical Meteorology. 2003, 55B, 966-81.

[55] Meylan W. 1999, (Syracuse Research Corporation: New York).

[56] Karickhoff SW. Semi-empirical Estimation of sorption of hydrophobic pollutants on natural sediments and soils. Chemosphere. 1981, 10(8), 833-46.

[57] Reimers CE, Suess E. The partitioning of organic carbon fluxes and sedimentary organic matter decomposition rates in the ocean. Marine Chemistry. 1983, 13, 141-68.

[58] Mackay D. Multimedia environmental models: the fugacity approach 2001 (Lewis Publishers: Boca Raton).

[59] Warren CS, Mackay D, Bahadur NP, Boocock DGB. A suite of multisegment fugacity models describing the fate of organic contaminants in aquatic systems: application to the Rihand Reservoir, India. Water Research. 2002, 36, $4341-55$.

[60] Mackay D, Paterson S, Shiu WY. Generic models for evaluating the regional fate of chemicals. Chemosphere. 1992, 24(6), 695-717.

[61] Koelmans AA, Anzion SF, Lijklema L. Dynamics of Organic Micropollutant Biosorption to Cyanobacteria and Detritus. Environmental Science \& Technology. 1995, 29, 933-40.

[62] Reynolds CS. Ecology of Phytoplankton 2006 (Cambridge University Press: New York).

[63] Baird ME, Oke PR, Suthers IM, Middleton JH. A plankton population model with biomechanical descriptions of biological processes in an idealised 2D ocean basin. Journal of Marine Systems. 2004, 50, 199 - 222.

[64] Cincinelli A, Martellini T, Del Bubba M, Lepri L, Corsolini S, Borghesi N, King MD, Dickhut RM. Organochlorine pesticide air-water exchange and bioconcentration in krill in the Ross Sea. Environmental Pollution. 2009, 157(7), 2153-8.

[65] Dickhut RM, Cincinelli A, Cochran M, Ducklow HW. Atmospheric Concentrations and Air-Water Flux of Organochlorine Pesticides along the Western Antarctic Peninsula. Environmental Science \& Technology. 2005, 39, 465-70. 


\section{Tables}

Table 1: Literature and calibrated ecosystem parameter values.

\begin{tabular}{|c|c|c|c|c|}
\hline \multirow[b]{2}{*}{ Par } & \multirow{2}{*}{ Description } & \multirow{2}{*}{ Units } & \multicolumn{2}{|c|}{ Value } \\
\hline & & & Baseline & Calibrated \\
\hline$\mu$ & $\begin{array}{l}\text { Maximum phytoplankton } \\
\text { growth rate }\end{array}$ & $\mathrm{h}^{-1}$ & $0.04125[54]$ & 0.0182 \\
\hline$\kappa$ & $\begin{array}{l}\text { Phytoplankton nutrient half- } \\
\text { saturation }\end{array}$ & $\mathrm{mgN} \mathrm{m}^{-3}$ & $19.1[54]$ & 8.675 \\
\hline$\varphi$ & $\begin{array}{l}\text { Zooplankton grazing rate on } \\
\text { phytoplankton }\end{array}$ & $\mathrm{m}^{3} \mathrm{mgN}^{-1} \mathrm{~h}^{-1}$ & $0.00108[54]$ & $2.55 \times 10^{-3}$ \\
\hline$\sigma_{P}$ & Phytoplankton mortality rate & $\mathrm{h}^{-1}$ & $1.0 \times 10^{-4}$ & $9.10 \times 10^{-6}$ \\
\hline$\psi$ & $\begin{array}{l}\text { Zooplankton assimilation } \\
\text { efficiency }\end{array}$ & - & $0.37[54]$ & 0.392 \\
\hline$\sigma_{Z}$ & Zooplankton mortality rate & $\mathrm{h}^{-1}$ & $0.0012[54]$ & $2.82 \times 10^{-3}$ \\
\hline$v$ & Detritus remineralisation rate & $\mathrm{h}^{-1}$ & $0.0042[19]$ & $4.17 \times 10^{-3}$ \\
\hline$N_{T}$ & Maximum nutrient & $\mathrm{mgN} \mathrm{m}^{-3}$ & - & 3.26 \\
\hline
\end{tabular}


Table 2: Description of parameters, units, values, and derivation where appropriate for the fugacity equations.

\begin{tabular}{|c|c|c|c|c|}
\hline Par & Parameter Description & Derivation & Value & Units \\
\hline$T$ & Air Temperature & & $\begin{array}{l}257-272.5 \\
{[35]}\end{array}$ & $\mathrm{K}$ \\
\hline$S S T^{1}$ & Sea Surface Temperature & AVHRR & $\begin{array}{l}271.5- \\
275.5\end{array}$ & $\mathrm{~K}$ \\
\hline$H$ & $\begin{array}{l}\text { Reference HCB Henry's Law } \\
\text { Constant }\end{array}$ & & $172[55]$ & $\begin{array}{l}\mathrm{Pa} \mathrm{m}^{3} \\
\mathrm{~mol}^{-1}\end{array}$ \\
\hline$K_{o w}$ & $\begin{array}{l}\text { Reference HCB octanol/water } \\
\text { partition coefficient }\end{array}$ & & $537,032[55]$ & - \\
\hline$K_{o c}$ & $\begin{array}{l}\text { Reference HCB organic carbon } \\
\text { partition coefficient }\end{array}$ & $0.41 K_{o w}$ & $220,183[56]$ & - \\
\hline$P_{l}^{s}$ & $\begin{array}{l}\text { Reference HCB sub-cooled liquid } \\
\text { vapour pressure }\end{array}$ & & $0.267[55]$ & $\mathrm{Pa}$ \\
\hline$f_{o c}$ & $\begin{array}{l}\text { Fraction organic carbon in } \\
\text { sediment }\end{array}$ & & $0.02[14]$ & \\
\hline$\rho_{S}$ & Density of sediment & & $2.3^{[57]}$ & $\mathrm{kg} \mathrm{L}^{-1}$ \\
\hline$A_{W}$ & Air-water interface area & & 1 & $\mathrm{~m}^{2}$ \\
\hline$A_{S}$ & Sediment-water interface area & & 1 & $\mathrm{~m}^{2}$ \\
\hline$V_{A}$ & Volume of air & & 1000 & $\mathrm{~m}^{3}$ \\
\hline$V_{W}$ & Volume of water & & 100 & $\mathrm{~m}^{3}$ \\
\hline$V_{s}$ & Volume of sediment & & 0.05 & $\mathrm{~m}^{3}$ \\
\hline$V_{P}$ & $\begin{array}{l}\text { Phytoplankton volume at steady } \\
\text { state }\end{array}$ & $\xi_{p} \gamma_{p} P^{*} V_{w}$ & & $\mathrm{~m}^{3}$ \\
\hline$V_{Z}$ & $\begin{array}{l}\text { Zooplankton volume at steady } \\
\text { state }\end{array}$ & $\xi_{z} \gamma_{z} Z^{*} V_{w}$ & & $\mathrm{~m}^{3}$ \\
\hline$V_{D}$ & Detritus volume at steady state & $\gamma_{d} D^{*} V_{w}$ & & $\mathrm{~m}^{3}$ \\
\hline$\omega$ & $\begin{array}{l}\text { Proportion of detritus in direct } \\
\text { contact with sediment }\end{array}$ & & 0.5 & - \\
\hline
\end{tabular}




\begin{tabular}{|c|c|c|c|c|}
\hline$N_{T}$ & Total amount of nutrients & & 3.5 & $\mathrm{mgN} \mathrm{m}^{-3}$ \\
\hline \multirow[t]{2}{*}{$Z_{A}$} & \multirow[t]{2}{*}{ Fugacity capacity for air } & 1 & $0.00044[58]$ & $\mathrm{mol} \mathrm{m} \mathrm{m}^{-3}$ \\
\hline & & $R T$ & & $\mathrm{~Pa}^{-1}$ \\
\hline \multirow[t]{2}{*}{$Z_{W}$} & \multirow[t]{2}{*}{ Fugacity capacity for water } & 1 & $0.0361[58]$ & mol m-3 \\
\hline & & $\overline{H(S S T)}$ & & $\mathrm{Pa}^{-1}$ \\
\hline \multirow[t]{2}{*}{$Z_{S}$} & \multirow[t]{2}{*}{ Fugacity capacity for sediment } & $K_{o c} f_{o c} \rho_{s}$ & $892[58]$ & $\mathrm{mol} \mathrm{m}{ }^{-3}$ \\
\hline & & $H(S S T)$ & & $\mathrm{Pa}^{-1}$ \\
\hline \multirow[t]{2}{*}{$Z_{P}$} & Fugacity capacity & $K_{o w} Z_{w}$ & $47275[59]$ & mol m-3 \\
\hline & phytoplankton & & & $\mathrm{Pa}^{-1}$ \\
\hline \multirow[t]{2}{*}{$Z_{Z}$} & capacity for & $K_{o w} Z_{w}$ & $47275[59]$ & $\mathrm{mol} \mathrm{m}{ }^{-3}$ \\
\hline & zooplankton & & & $\mathrm{Pa}^{-1}$ \\
\hline \multirow[t]{2}{*}{$Z_{D}$} & \multirow[t]{2}{*}{ Fugacity capacity for detritus } & $K_{o c} Z_{w}$ & $19383[59]$ & $\mathrm{mol} \mathrm{m}{ }^{-3}$ \\
\hline & & & & $\mathrm{Pa}^{-1}$ \\
\hline \multirow[t]{2}{*}{$Z_{x}$} & \multirow[t]{2}{*}{ Fugacity capacity for aerosols } & $6 \times 10^{6} Z_{a}$ & $107317[58]$ & $\mathrm{mol} \mathrm{m}^{-3}$ \\
\hline & & $P_{l}^{s}$ & & $\mathrm{~Pa}^{-1}$ \\
\hline \multirow[t]{2}{*}{$k_{V}$} & Air-water & & 0.000117 & $\mathrm{~m} \mathrm{~h}^{-1}$ \\
\hline & $\begin{array}{l}\text { volatilization/sorption mass } \\
\text { transfer coefficient }\end{array}$ & & [36] & \\
\hline$k_{T}$ & $\begin{array}{l}\text { Sediment-water diffusion mass } \\
\text { transfer coefficient }\end{array}$ & & $0.0001[60]$ & $\mathrm{m} \mathrm{h}^{-1}$ \\
\hline$k_{P U}$ & $\begin{array}{l}\text { Phytoplankton-water uptake } \\
\text { rate constant }\end{array}$ & & $4.57[30]$ & $h^{-1}$ \\
\hline$k_{P D}$ & $\begin{array}{l}\text { Phytoplankton-water } \\
\text { depuration rate }\end{array}$ & $\frac{k_{p u} Z_{W}(S S T)}{Z_{P}(S S T)}$ & & $\mathrm{h}^{-1}$ \\
\hline$k_{Z U}$ & $\begin{array}{l}\text { Zooplankton-water uptake rate } \\
\text { constant }\end{array}$ & & $5.67[31]$ & $\mathrm{h}^{-1}$ \\
\hline$k_{Z D}$ & $\begin{array}{l}\text { Zooplankton-water depuration } \\
\text { rate }\end{array}$ & $\frac{k_{z u} Z_{W}(S S T)}{Z_{Z}(S S T)}$ & & $\mathrm{h}^{-1}$ \\
\hline$k_{D W}$ & $\begin{array}{l}\text { Detritus-water depuration rate } \\
\text { constant }\end{array}$ & & $0.2^{[61]}$ & $\mathrm{h}^{-1}$ \\
\hline \multirow[t]{2}{*}{$k_{D S}$} & Detritus-sediment exchange & $\underline{B_{W}\left(1-V_{F}\right)^{1.5}}$ & $1.8 \times 10^{-5}$ & $\mathrm{~m} \mathrm{~h}^{-1}$ \\
\hline & mass transfer coefficient & $\ln 2 h_{s}$ & [12] & \\
\hline
\end{tabular}




\begin{tabular}{|c|c|c|c|}
\hline$\Phi$ & $\begin{array}{l}\text { Volume fraction occupied by } \\
\text { aerosols }\end{array}$ & $\begin{array}{l}8.5 \times 10^{-13} \\
{[38]}\end{array}$ & $\mathrm{g} \mathrm{m}^{-2} \mathrm{~h}^{-1}$ \\
\hline$\rho_{D}$ & Aeolian dust density & $2.3 \times 10^{6}$ & $\mathrm{~g} \mathrm{~m}^{-3}$ \\
\hline$U_{R}$ & Sediment resuspension rate & $\begin{array}{l}1.1 \times 10^{-8} \\
{[15]}\end{array}$ & $\mathrm{m} \mathrm{h}^{-1}$ \\
\hline$U_{D}$ & Sediment deposition rate & $\begin{array}{l}1.1 \times 10^{-8} \\
{[15]}\end{array}$ & $\mathrm{m} \mathrm{h}^{-1}$ \\
\hline$\gamma_{P}$ & $\begin{array}{l}\text { Phytoplankton mass-volume } \\
\text { conversion }\end{array}$ & $\begin{array}{l}5.33 \times 10^{-8} \\
{[62]}\end{array}$ & $\mathrm{m}^{3} \mathrm{mgN}^{-1}$ \\
\hline$\gamma_{z}$ & $\begin{array}{l}\text { Zooplankton mass-volume } \\
\text { conversion }\end{array}$ & $\begin{array}{l}5.33 \times 10^{-8} \\
{[63]}\end{array}$ & $\mathrm{m}^{3} \mathrm{mgN}^{-1}$ \\
\hline$\gamma_{D}$ & $\begin{array}{l}\text { Detritus mass-volume } \\
\text { conversion }\end{array}$ & $5.33 \times 10^{-8}$ & $\mathrm{~m}^{3} \mathrm{mgN}^{-1}$ \\
\hline$\xi_{P}$ & Phytoplankton lipid proportion & $0.1^{[62]}$ & - \\
\hline$\xi_{\mathrm{Z}}$ & Zooplankton lipid proportion & $0.045[8]$ & - \\
\hline$k_{L}{ }^{1}$ & $\begin{array}{l}\text { Diffuse attenuation coefficient } \\
\text { for seawater }\end{array}$ & 0.05 & $\mathrm{~m}^{-1}$ \\
\hline$T_{M A X}{ }^{1}$ & $\begin{array}{l}\text { Maximum seasonal sea surface } \\
\text { temperature from AVHRR }\end{array}$ & 2 & ${ }^{0} \mathrm{C}$ \\
\hline$I_{S A T^{1}}$ & $\begin{array}{l}\text { Saturating photosynthetically } \\
\text { available irradiance }\end{array}$ & 35 & $E m^{-2} d^{-1}$ \\
\hline
\end{tabular}

${ }^{1}$ Values obtained from satellite data 
Table 3: Published observations of HCB concentrations in Antarctica in various phases and steady state model fugacities calibrated so that total mass in the simulated closed environment was $5 \times 10^{-7}$ mol HCB.

\begin{tabular}{lccc}
\hline \multicolumn{1}{c}{ Phase } & \multicolumn{1}{c}{ Concentration } & \multicolumn{2}{c}{ Fugacity (Pa) } \\
\cline { 3 - 4 } & & Calculated & Model \\
\hline Air & $8.5-28.1 \mathrm{pg} / \mathrm{m}^{3}[64,65]$ & $6.8 \times 10^{-11}-2.2 \times 10^{-10}$ & $1.3 \times 10^{-8}$ \\
Water & $1.72-16.24 \mathrm{pg} / \mathrm{L}[64]$ & $1.7 \times 10^{-10}-1.6 \times 10^{-9}$ & $3.2 \times 10^{-8}$ \\
Sediment & $\sim 2-4 \mathrm{ng} / \mathrm{g}[45]$ & $1.8 \times 10^{-11}-3.6 \times 10^{-11}$ & $8.5 \times 10^{-9}$ \\
Phytoplankton & $15.9 \pm 6.2 \mathrm{ng} / \mathrm{g}$ lipid ${ }^{[50]}$ & $6.6 \times 10^{-10}-1.5 \times 10^{-9}$ & $3.7 \times 10^{-10}$ \\
Zooplankton & $1.4-8.4 \mathrm{ng} / \mathrm{g} \mathrm{lipid}[8]$ & $9.5 \times 10^{-11}-5.7 \times 10^{-10}$ & $8.5 \times 10^{-10}$ \\
Detritus & - & - & $3.2 \times 10^{-8}$ \\
\hline
\end{tabular}




\section{Figures}

\section{Figure Captions}

Figure 1: Processes in physical and biological systems. The arrows between circular compartments represent the movement of inorganic nitrogen while the arrows between square compartments and arrows between the air, water and sediment represent the movement of POPs. Arrow 1 is uptake of nutrients by phytoplankton, 2 is consumption by zooplankton, 3 is phytoplankton mortality, 4 is zooplankton mortality and respiration and 5 is detritus remineralisation. 6 is volatilisation/sorption, 7 is dry deposition, 8 is wet deposition, 9 is watersediment diffusion, 10 is resuspension, 11 is deposition, 12 is phytoplankton uptake/depuration, 13 is consumption by zooplankton, 14 is phytoplankton mortality, 15 is zooplankton uptake/depuration, 16 is zooplankton mortality and respiration, 17 is detritus-water diffusion and 18 is detritus-sediment exchange.

Figure 2: Seasonal cycle of the biomass of phytoplankton (solid line), zooplankton (dotted line), detritus (dashed line) and SeaWiFS measurements of chlorophyll, converted to biomass equivalent (open circles).

Figure 3: First order sensitivities of the steady state relative fugacities of the compartments to 30 selected parameters: air (a), water (b), sediment (c), phytoplankton (d), zooplankton (e) and detritus (f).

Figure 4: Second order sensitivities of the steady state relative fugacities to the 30 most important two-parameter combinations. Panels and parameter numbering as for Figure 3. 
Figure 5: Sensitivity of food web biomagnification factor (BMF) to individual parameters (left panel) and important two-parameter combinations (right panel). Parameter numbering as for Figure 3.

Figure 6: Seasonal cycle of the fugacity of HCB in air (a), water (b), sediment (c), phytoplankton (d), zooplankton (e) and detritus (f).

Figure 7: Seasonal cycle of the mass of HCB in air (a), water (b), sediment (c), phytoplankton (d), zooplankton (e) and detritus (f).

Figure 8: Seasonal cycles of the diffusive exchange of HCB mass between water and air (a), sediment (b), phytoplankton (c), zooplankton (d), and detritus (e). All these movements of mass are with respect to water, therefore positive fluxes indicate a movement of HCB mass into the water phase. Panel (f) shows the diffusive exchange of HCB mass between detritus and sediment (positive values show movement of HCB from detritus to sediment).

Figure 9: Seasonal cycles of the movement of HCB mass due to ecosystem processes: phytoplankton mortality (a), zooplankton grazing (b), zooplankton respiration (c), and zooplankton mortality (d); and net movement of HCB mass through the phytoplankton (diffusion - grazing - mortality, e) and net movement of HCB mass through the zooplankton (diffusion + growth - respiration mortality, f). All movements of mass are with respect to respective phase, therefore positive fluxes indicate a movement of HCB mass into the phase.

Figure 10: Seasonal cycle of the biomagnification of HCB concentration in zooplankton. 